January 2006

\title{
Welfare, Cash Grants, and Marginal Rates
}

Daniel N. Shaviro

\section{Recommended Citation}

Daniel N. Shaviro, Welfare, Cash Grants, and Marginal Rates, 59 SMU L. REV. 835 (2006)

https://scholar.smu.edu/smulr/vol59/iss2/15

This Article is brought to you for free and open access by the Law Journals at SMU Scholar. It has been accepted for inclusion in SMU Law Review by an authorized administrator of SMU Scholar. For more information, please visit http://digitalrepository.smu.edu. 


\section{Welfare, Cash Grants, and Marginal Rates}

Daniel N. Shaviro*

\section{INTRODUCTION}

W

HEN we think about transfer payments, such as those under Temporary Aid to Needy Families ("TANF") or Food Stamps, we should recognize that they are negative taxes. Just like income taxes, they involve cash flows between private parties and the government, albeit going in the opposite direction. Moreover, no less than income tax payments, their amount is based on a measure of material well-being.

Many economists and lawyers have understood that transfers are negative taxes at least since Richard Musgrave published his landmark treatise, The Theory of Public Finance, in 1959.1 Yet the point has so little penetrated public discourse that, even among experts, few seem to keep it in mind when discussing such basic questions as what the marginal tax rate structure in our country either actually is or ought to be.

Consider two truisms-or actually, falsisms - that are so conventional as to seem almost banal. Both concern the degree of graduation of marginal rates, or the extent to which they increase with income. The first holds that graduated marginal rates are the defining attribute of a progressive system. Thus, the renowned and still frequently cited 1953 study by Walter Blum and Harry Kalven, The Uneasy Case for Progressive Taxation, takes as its subject the justifiability of the graduated marginal rate structure of the income tax. ${ }^{2}$ Blum and Kalven decline, on grounds of unfeasibility, to examine progressivity in terms of the relationship between taxes and benefits. The second widely accepted truism holds that the United States actually has graduated marginal rates at present, in that poor people pay the lowest marginal rates.

Neither of these two truisms is actually true. First, graduated marginal rates are not necessary for progressivity, defined more meaningfully in terms of the fiscal system's overall treatment of the poor and the rich.

* Wayne Perry Professor of Taxation, NYU Law School. A longer version of this article will appear as chapter 9 of Daniel N. Shaviro, Taxes, Spending, and the U.S. Government's March Towards Bankruptcy, to be published by the Cambridge University Press 2006. This article is reproduced by permission of Cambridge University Press.

1. Richard Musgrave, The Theory of Public Finance: A Study in Public ECONOMY (1959).

2. Walter Blum \& Harry Kalven, The Uneasy Case for Progressive TaxaTION (1953). 
Indeed, having low marginal rates in lower income ranges may not be a good idea even if one favors significant progressivity. Second, marginal rates often are highest for poor people, and to a degree that might widely be considered shocking if it were better understood. Indeed, the marginal rates for some poor and near-poor individuals are so high, approaching or even exceeding one hundred percent, that they create harsh "poverty traps" that frustrate people's efforts to better their circumstances through work. The fact that marginal rates need not be as low as is commonly thought near the bottom of the income distribution does not mean that they should be anywhere near one hundred percent.

The poverty traps result from rapidly phasing out transfers, such as TANF, Food Stamps, Medicaid, the earned income tax credit ("EITC"), and housing subsidies. The rapidity of the phase-outs reflects the common view that only poor and near-poor people should get these transfers. As you leave poverty, therefore, you may rapidly lose many thousands of dollars worth of benefits, on top of also paying various positive taxes on your earnings.

Why has a view of transfers as negative taxes, and of phase-outs as imposing tax rates, not caught on more generally? The problem is one of fiscal language. Transfers are labeled "spending" rather than taxes. In addition, it is hard to dissuade people from treating as significant the formally designated boundaries of particular distinct programs, even though the whole is what really matters. Thus, it seems abhorrent for anyone who is not poor to get "welfare," regardless of how she does overall.

It is not as if supporters of significant aid to the poor want such aid to come at the price of creating poverty traps. Fiscal language simply makes this ugly trade-off seem necessary, reflecting not just prevailing conventions but also underlying psychological heuristics. One such heuristic is the endowment effect, which encourages unduly distinguishing between a dollar paid out by the Treasury and a dollar that never is paid in. Another is the inclination to create multiple distinct "mental accounts through which losses and gains, including losses and gains in simple monetary terms, are not fungible with each other." 3 This way of thinking encourages evaluating formally distinct programs separately, as an intuitive preference rather than simply because the broader picture requires more information.

\section{WELFARE VERSUS CASH GRANTS: IS THE DISTINCTION PURELY SEMANTIC?}

\section{A. Welfare for Bill Gates??}

I would not want to be the brave politician who proposed a welfare program under which Bill Gates got benefits. The awkwardness of making such a proposal is one reason why George McGovern was so widely

3. Cass R. Sunstein, Introduction to Behavioral. Law AND Economics 6 (Cass R. Sunstein ed., 2000). 
mocked and condemned, during the 1972 presidential campaign, when he proposed a $\$ 1,000$ per person "demogrant."4 It did not help McGovern, in trying to fend off accusations of far-left quackery, that his idea had features in common with a "Family Assistance Plan" that President Nixon had been promoting within the past year. ${ }^{5}$ Nor did it help that demogrants or similar benefits had been endorsed, not only by the liberal economist James Tobin, ${ }^{6}$ but by such conservative icons as Friedrich Hayek, ${ }^{7}$ George Stigler, ${ }^{8}$ and Milton Friedman. ${ }^{9}$ Part of the problem was that the McGovern campaign had not thought through the plan very well before unveiling it. Another problem, to which I will return shortly, is that the idea of a universal guarantee raised concern about rewarding and encouraging idleness, and ran afoul of the widely held belief that people who decline to work do not deserve support.

It nonetheless is worth asking the full question on the merits: should Bill Gates get welfare benefits?

"Obviously not," one might be inclined to answer. But the correct answer is that it does not matter, if we care about the fiscal system's effects as a whole, rather than about the functioning of particular formally designated parts. What is more, the question of whether Gates should get the benefits is hard to make sense of, when even the question of whether he actually does get them can only be answered formalistically.

Starting with the point that it does not matter, suppose we have two choices. The first is to deny Gates welfare benefits while keeping his current tax liability constant. The second is to give him $\$ 5,000$ of welfare benefits, but simultaneously to increase his taxes by $\$ 6,000$. Does anyone really think that the second alternative unfairly benefits him relative to the first, given that it leaves him $\$ 1,000$ worse off? And, if one is concerned about "cutting [him] that completely unneeded check"10_although why this should matter, in today's world of electronic transactions, is unclear-would it help if the welfare benefits were simply credited against his income tax liability? Then he would be directly "getting" the benefits in one sense, since there would be a line on his tax return crediting them, but not in another, since he would never actually receive a $\$ 5,000$ check.

In what sense, however, does Bill Gates currently not get welfare benefits? We can be certain that he does not go to see a caseworker at the Department of Social and Health Services in the state of Washington, requesting TANF cash benefits, and that if he did go, his prospects of

4. Editorial, McGovernomics, N.Y. TIMEs, Aug. 30, 1972, at 36.

5. See Martha B. Coven, The Freedom to Spend: The Case for Cash-Based Public Assistance, 86 MinN. L. REv. 847, 868 (2002).

6. See James Tobin, The Case for an Income Guarantee, 4 Pub. INT. 31, 36-38 (1966).

7. See Friedrich A. Hayek, The Road to Serfoom 133 (1944).

8. See George Stigler, The Economics of Minimum Wage Legislation, 36 Ам. Econ. REv. 358, 365 (1946).

9. See Milton Friedman, Capitalism and Freedom 191 (1962).

10. Fred Block, Why Pay Bill Gates?, in What's Wrong With a Free Lunch? 86 (Phillipe Van Parijs ed., 2001). 
establishing eligibility would be slim. In a formal or literal sense, therefore, he indeed does not receive welfare benefits.

Gates does, however, lose out on various benefits because his income and assets are too high. After all, he presumably would be eligible for welfare benefits if he and his wife, along with their three young children, had nothing at all. This means-related loss of benefits could alternatively be accomplished, without changing either gross or net cash flows, by restructuring his income tax return so that he both (1) got a tax credit for the full benefit that he would have received with zero income and assets, and (2) was subject to a "welfare phase-out tax," collected via the income tax return although using the welfare system's measure of means, and equaling the full amount of the credit.

To make this look a bit more like existing welfare, we might add one further administrative detail that would make no substantive difference. We could have the state of Washington provide that anyone who does not go to see a Department of Social and Health Services caseworker is nonetheless allowed the welfare tax credit, but is conclusively presumed to owe a welfare phase-out tax that equals the full credit. Moreover, we could provide that those who did come in to see a caseworker would not only avoid this presumption, but could elect to get a check for any net cash that was due, rather than having to claim a refundable credit from the income tax authorities.

If the means test for welfare benefits were conformed to the federal definition of taxable income so that the same computation governed both systems, it would be even simpler to re-describe Bill Gates as a recipient of welfare benefits. Now the tax credit for welfare benefits at zero income could simply be offset by higher marginal rates in the lower income echelons, without requiring a distinct "welfare phase-out tax" based on a different income measure. So the only observable instruments would be the income tax with its restated rates, the refundable welfare tax credit, and the rule requiring application to a caseworker for direct payment.

Under this system, Bill Gates would apparently be getting welfare benefits as under the McGovern demogrant, rather than not getting them as under present law. Yet nothing about his overall treatment by the fiscal system would actually have changed.

\section{B. What Should the Grants be Called?}

The idea that Friedrich Hayek, George Stigler, Milton Friedman, James Tobin, Richard Nixon, George McGovern, and Daniel Patrick Moynihan (the principal architect of Nixon's Family Assistance Plan) all advocated goes by a number of different names. The leading terms, some of which only describe particular variants, include not only "demogrant" but "basic income," "guaranteed income," and "negative income tax." As Tobin, Joseph Pechman, and Peter Mieszkowski explained:

These proposals can be described and compared in terms of two identifying features: the basic allowance which an eligible individual 
or family may claim from the government, and the offsetting tax which every recipient of the basic allowance must pay on his other income. The net benefit to the recipient is the basic allowance less the offsetting tax. ${ }^{11}$

In lieu of any of these terms, I will use the admittedly imperfect term "cash grant" for several reasons. The terms "demogrant," "basic income," and "guaranteed income" have negative political connotations, due partly to the McGovern episode but also to their apparent implication that everyone should get the grant. This runs afoul of the view that, as critics of the Family Assistance Plan argued, we should not use cash grants "to show able-bodied people how they can avoid going to work." 12 "Income support" is better, except that it fails to signal the distinction from traditional welfare.

Identifying the cash grant idea with universality is not just politically inconvenient, but misleading. Fiscal language games are not likely to permit one to dodge public aversion to giving out universal grants if that, in fact, is what one is doing. However, the question of whether cash grants should be universal is no different from the question of whether welfare benefits should be universal. Either can be provided to everyone or just to qualified individuals.

The only distinction between cash grants and welfare benefits, as I will use the terms, is that welfare benefits are expressly means-tested, while cash grants are not. In the case of a cash grant, the use of income or asset tests take place only outside the formal boundaries of the program, although the overall results could be exactly the same as under welfare. In short, speaking of cash grants rather than of welfare is purely a fiscal language change, not necessarily associated with any overall policy difference. As we will see, however, there is a reason for it.

The term "negative income tax" arguably has greater descriptive merit than the other customary terms, including "cash grant." In addition to not implying the universality that might or might not be a program feature, the term "negative income tax" has the descriptive virtue of emphasizing the symmetry between paying a net tax and getting a net benefit. ${ }^{13}$ But it not only shares in the unfortunate history of the term "demogrant," but is also further removed than "cash grant" from what arguably is a better term than either: "non-income-conditioned cash grant." Such a term seems unacceptably turgid, however. "Cash grant" as simply a shorthand version of it.

One further problem with the term "cash grant"-shared, however, by "negative income tax" if we think of "taxes" as necessarily involving cash-is that certain benefits for the poor are provided in kind, or else

11. James Tobin, Joseph Pechman \& Peter Mieszkowski, Is a Negative Income Tax Practical?, 77 Yale L.J. 1, 2 (1967).

12. Daniel Patrick Moynihan, The Politics of a Guaranteed Income: The Nixon Administration and the Family Assistance Plan 485 (1973).

13. Tobin et al., supra note 11 , at 2. 
through the use of vouchers that can only be used for specified purposes. Prominent examples include Food Stamps, Medicaid, and housing subsidies. The issues raised by providing such benefits in lieu of cash ${ }^{14}$ are distinct from the fiscal language point being considered here. To give Bill Gates Food Stamps clearly would matter administratively, even if he remained in the same position overall due to paying extra offsetting taxes and keeping his overall food expenditures constant. For Medicaid, which is not simply a voucher for the purchase of $\$ X$ worth of medical services, the differences are more than just administrative. Again, however, the choice between cash and in-kind benefits is distinct from the fiscal language choice between "welfare" and "cash grant."15

What "cash grant" really is shorthand for, then, is "non-income-conditioned cash or in-kind grant." I trust readers will forgive me for not using the longer term.

\section{The Cash Grant Description Versus the Welfare Description of a Given Policy}

To further show how formal descriptions do and don't matter, a simplified example of aid to the poor may help. Suppose the poverty line in a given jurisdiction is defined as $\$ 20,000$. Initially, there is only a thirty percent income tax from which the poor are exempted. That is, everyone gets a $\$ 20,000$ exemption, creating a zero tax rate on income up to that amount. Any income over that amount is taxed at thirty percent.

The legislature then decides that no one residing in the jurisdiction should be forced to live on less than $\$ 15,000$, or three-quarters of the poverty line. This amount will be given to people with zero income. The amount that people get will be reduced as income rises, and at some point they will once again be paying a net tax. In addition, tax rates will have to go up somewhere in order to finance the new benefit.

Suppose initially that the designers think of the program as conventional welfare. Therefore, they conclude that only the poor should get it. In particular, no one who is earning more than $\$ 20,000$ should get it. They might provide that, for every extra dollar a poor person earns, the benefit is reduced by seventy-five cents. That way, the constraints of paying $\$ 15,000$ to someone who earns zero and nothing to someone who earns $\$ 20,000$ are satisfied on a straight-line basis.

Suppose further that, in order to fund the benefit, the positive tax rate must be raised from thirty percent to thirty-five percent. Effectively, there are now two tax brackets, with marginal rates of seventy-five per-

14. See generally David F. Bradford \& Daniel Shaviro, The Economics of Vouchers, in Vouchers and the Provision of Public Services (C. Eugene Steuerle et al. eds., 2000).

15. In-kind benefits could be provided without requiring that Bill Gates get Food Stamps. For example, in-kind benefits could gradually be scaled back, with the lost portion being converted into cash, as income increased, with no effect on the marginal tax rate (which could be determined separately) except insofar as the conversion affected subjective value because not equated by recipients with the cash equivalent. 
cent on income up to $\$ 20,000$ and thirty-five percent above that point. However, the seventy-five percent bracket was not chosen through an evaluation of proper rate structures. Rather, it was forced on the designers by their decision to eliminate the benefit by the time one reaches the poverty line.

Now suppose instead that the designers opt for a $\$ 15,000$ universal cash grant, to be funded by eliminating the zero bracket and making such other rate increases as may be necessary. The designers might start with a thirty-five percent rate that now applies without any exemption amount. Unfortunately, this will not raise enough revenue given the numbers in the first example, where the break-even tax brackets were seventy-five percent and thirty-five percent. The designers must increase the marginal tax rate somewhere in the income range.

One possibility would be to adopt a seventy-five percent marginal tax rate on everyone's first $\$ 20,000$ of income. If the designers do this (and we already know from the first example that it raises the right amount of revenue), then the two systems are identical. In both cases, everyone pays (a) seventy-five percent of the first $\$ 20,000$ of income, plus (b) thirty-five percent of all additional income, minus (c) $\$ 15,000$, with any excess of (c) over [(a) plus (b)] being refundable by the government.

The big procedural difference is that the designers in the second case have given themselves more freedom in setting the marginal rate structure. Rather than boxing themselves in at the start by stipulating the maximum benefit and the point at which it must be gone, they have allowed themselves to think in terms of what marginal rate structure is best, and thus to adopt either the very same scheme or else a different one.

This greater freedom could make all the difference in the world. Suppose that a seventy-five percent marginal rate is simply too high given its incentive effects. Only the second methodology eliminates the risk of imposing excessive marginal rates by mistake. ${ }^{16}$

There is a kind of sledgehammer irony to our having combined the view that marginal rates should be progressively graduated, with using a welfare description that invites ignoring the marginal rate effects of phasing out aid to the poor. After excluding as a matter of principle the idea that marginal rates might reasonably be higher in the low income brackets, we end up not even looking at what those rates actually are. The result has been not merely non-graduated rates, but some that are affirmatively confiscatory and in sharp conflict with making work pay.

16. In principle, the welfare description can be just as flexible as the cash grant description. Suppose that the best marginal rate structure in the earlier example would involve a fifty percent marginal rate on the first $\$ 30,000$ of income and a flat thirty-eight percent rate above that. All we would need do to get there under the welfare description is to say that the $\$ 15,000$ maximum benefit should not be fully phased out until income reaches $\$ 30,000$, and that $\$ 30,000$ should also be the income tax exemption amount. Other combinations of the phase-out rate and the income tax marginal rate could work identically, since an increase to either rate could be offset by reducing the other rate. The hard part is getting to the right answer from an inquiry that starts by asking who should get welfare benefits, rather than what the marginal rate structure should look like. 


\section{Cash Grants Versus Welfare in Relation to WORK INCENTIVES}

Both welfare and cash-grant style proposals, such as President Nixon's Family Assistance Plan, have been criticized at times for blunting work incentives. This issue played an important role in the welfare reform legislation enacted in 1996. ${ }^{17}$ Welfare reform, among other changes, set strict work requirements and imposed a five-year lifetime limit on eligibility for benefits ${ }^{18}$.

Before evaluating the significance of work incentives, we must start by clarifying what they are. When economists discuss the effects of fiscal rules on work incentives, they generally have in mind the impact of the rules on the net payoff from working. Hence, the higher the marginal tax rate, the more one's incentive to work is blunted. Within this terminology, handing someone a ten million dollar check would not be regarded as affecting her work incentives, except indirectly if it brought about a change in her marginal rate bracket. Those using this terminology recognize, of course, that someone who had an irksome and low-paying job would almost certainly quit if she got a ten million dollar check. This, however, is classified as an income or wealth effect that alters her choice under a constant set of preferences.

In popular usage, by contrast, the notion of work incentives includes income effects. While imposing, a ninety-five percent marginal tax rate on poor people would certainly be understood to dampen their work incentives, the term also would extend to giving able-bodied individuals, who could have found jobs if sufficiently motivated, enough resources to meet their basic needs without working. Hence, a cash grant, and certainly a universal demogrant, would be criticized in common usage for dampening poor people's work incentives even if their marginal rates were reduced.

Work incentives in the economist's sense matter for reasons of efficiency. If Smith would be willing to pay Jones up to $\$ 10$ to perform a given task and Jones would be willing to do it so long as he got at least $\$ 7$, the deal between them would create $\$ 3$ of surplus (the excess of the value to Smith of having the task done over the disvalue to Jones of doing it). If the deal was subject to a forty percent tax, it presumably would not get done. The tax would have prevented the realization of this social surplus, without anyone's benefiting (since the government gets no revenue from a deal that fails to happen).

This analysis does not, however, apply to work incentives in the popular sense. If Jones is given enough money to meet his basic needs and decides that he does not want to do the task even for $\$ 10$, then evidently his disvalue (given his new circumstances) now exceeds the value to

17. Personal Responsibility and Work Opportunity Reconciliation Act of 1996, Pub. L. No. 104-93, 110 Stat. 2260.

18. Id. 
Smith. From this standpoint, withholding aid from able-bodied poor people, on the ground that they will not work if their basic needs are already met, would make no more sense than telling millionaire professional athletes that they cannot retire just because they are already rich.

But this is not to say that popular concern about "work incentives" is wrong; only that it must rest on some other ground. The claim could be cognitive error by poor people when they are deciding whether to work. For example, they might be thought to under value the benefits of learning to function in the workplace or of increasing their earning capacity for the future. On the other hand, the claim might be that work has positive externalities, such as reducing crime levels, setting better behavioral models for children, or simply relieving taxpayers of the need to provide support.

Cash grants clearly affect work incentives in the popular sense. Just as under the welfare definition, however, policymakers who consider this undesirable can respond in a number of different ways. One approach would be to limit eligibility on some basis other than income. Thus, cash grants could be limited to a sub-class of the population that is not expected to work, such as seniors and the disabled.

Another possible limit is work requirements, as under TANF. This makes the marginal rate analysis more complicated. A work requirement may in effect impose a minimum income requirement for the grant, resulting in a wage subsidy (a negative tax rate on earnings) in the range where one increases one's net transfer by working. Time limits on eligibility, which amount to disqualification for subsequent cash grants if one's income for each of the requisite number of years is sufficiently low, have similar effects.

The difficulty of drawing a clean line between income conditioning and other types of limits on grant eligibility should not, however, obscure the two central advantages of the cash grant description of benefits to the poor. Again, the first of these is the attention it focuses on overall marginal rates, rather than just on those associated with particular instruments within the fiscal system. The second advantage of the cash grant description is its making the entire marginal rate structure a matter of deliberate choice, without requiring extremely high rates in lower income ranges simply as a consequence of an arbitrary constraint holding that particular distinct benefits must be limited to the poor.

\section{E. Cash Grants Versus Welfare in Evaluating "Program COST" AND "TARgETING" OF BENEFITS}

Welfare experts have long recognized the issue of work incentives in the economist's sense. However, the language of "spending" can affect the apparent nature of the trade-offs in policy design, potentially encouraging worse policy outcomes.

If welfare is a distinct "spending" program, then slowing down a benefit phase-out appears to increase the cost of the program. Thus, recall the 
earlier example in which a decision has been made to offer $\$ 15,000$ to eligible individuals with zero income, phasing down to zero when income reaches $\$ 20,000$. Such a program would have a measurable direct budgetary impact, equaling the cash disbursed under it plus the costs of administration. ${ }^{19}$ Suppose initially that changing the size of the basic cash grant is not an option. Slowing down the phase-out, by reducing the marginal rate in the benefit reduction range from seventy-five percent to fifty percent, and thus changing the phase-out point to $\$ 30,000$, would substantially raise the program's direct budgetary cost.

Under a cash grant description, "program cost" would not in this sense be an issue. We would simply be changing net taxes and net grants for people in various income groups. In particular, people earning zero to $\$ 20,000$ would gain financially and have their marginal rates reduced, while those earning from $\$ 20,000$ to $\$ 30,000$ would gain financially but have their marginal rates increased. Those earning more than $\$ 30,000$, if their taxes were increased to pay for the change, would lose financially and might also experience an increase in their marginal rates. This is an important set of changes, but calling it a "spending increase" encourages a false analogy to, say, increasing highway spending, which directly changes the mix of the assets in the society rather than simply shifting dollars and marginal rates around between groups.

If the only available choice lies between a seventy-five percent phaseout and a fifty percent phase-out of a fixed $\$ 15,000$ grant, few advocates of aid to the poor are likely to have any objection to shifting from the former to the latter. After all, reducing the phase-out rate to fifty percent is a win-win proposition so far as the poor and near-poor are concerned. Suppose instead, however, that the size of the cash grant is also in play. Under this scenario, shifting to the slower phase-out would imply making the cash grant smaller if the "program size" (that is, the maximum feasible financial impact on higher-income taxpayers) is fixed. It would thus favor the near-poor relative to the poor, worsening the "targeting" of aid to the poorest individuals. While the trade-off is clear, and generally rightly understood even under prevailing fiscal language, it might be easier to avoid politically if the choice were framed as involving distribution between all groups rather than as higher versus lower "government spending."

Looking at the problem this way helps to show how misguided it is to assume that progressive fiscal systems must have graduated marginal rates. The goal of keeping poorer people's marginal rates lower than those of richer people, without regard to the size of the cash grant at the bottom, completely ignores one of the two key distributional variables. Why should the marginal rates that happen to be imposed at the middle and top of the income distribution have any bearing on how one resolves

19. There might also be indirect budgetary effects by reason of changes to people's work decisions. 
the trade-off at the bottom between providing an adequate minimum and avoiding excessive work disincentives?

\section{ACTUAL MARGINAL RATES IN THE U.S. FISCAL SYSTEM FOR POOR AND NEAR-POOR INDIVIDUALS}

The marginal rates faced by poor and near-poor individuals are of interest even if one rejects the need for rate graduation. Marginal rates determine how much extra economic reward one gathers, after accounting for the effects on taxes and transfers, by reason of earning more. This, in turn, matters for both incentive and distributional reasons. It affects work effort insofar as people respond to economic rewards, and it determines the extent to which high earners do better than low earners.

Unfortunately, the marginal rates that poor and near-poor individuals face are hard either to determine or summarize concisely for a number of different reasons, including the following:

1) Interstate variations - Programs that aid the poor, although subject to extensive federal law and regulation, are in many key respects (including benefit levels and phase-out rates) set at the state level. As a result, there are at least fifty different sets of marginal rate structures that a given household could face, depending on where it is situated, and more to the extent of intrastate variation between localities.

2) Different household types-Benefits are highly sensitive to household characteristics, such as the number of adults and/or children. In general, aid to the poor is far more generous for households with children than to those without. Given the belief that rapid phase-out is necessary, this causes households with children, though treated more favorably, to face much higher marginal rates, since much larger benefits are being phased out over what remains a compressed income range.

3) Variation in program design-Even when different programs are designed in similar ways, such as to increase benefits with the number of dependent children and to phase out benefits as income rises, there are often significant differences in their details, reflecting that they may have been separately designed by different people at different times. Thus, such important details as who is included in a given household and how income or assets are measured may vary between programs, leading to even more of an individualized polyglot of rate structures.

4) Differences in take-up or participation rates-Eligible individuals often do not participate in a given program, whether due to lack of information, discouragement by procedural hurdles, or simply personal preference. In addition, income-conditioned federal housing subsidies, which can provide substantial benefits, are rationed, with the consequence that not all equally eligible households receive them. ${ }^{20}$ Non-participation in a

20. Daniel N. Shaviro, Effective Marginal Tax Rates on Low-Income Households, 84 TAX Notes 1191, 1194 (1999). 
program lowers one's benefit, but also one's marginal rate in the phaseout range.

5) Accrual of Social Security benefits-While Social Security payroll taxes, which have no exemption for low-earners, are among the positive inputs to marginal rates, Social Security benefits are in effect a wage subsidy. Retirement benefits generally increase with earnings in one's thirtyfive highest earning years that are subject to the Social Security tax. Should we therefore not include the full Social Security payroll tax when determining low-earners' marginal rates, at least for earning years that are likely to be among one's top thirty-five? In part, this depends on whether we are interested, for a given purpose, in actual net taxes paid on a lifetime basis, or in the perceived marginal rates that people use when making labor supply decisions. When we are interested in perceived rates, there is an argument for ignoring the accrual of retirement benefits, on the view that people generally do not understand it. ${ }^{21}$ Or, they may apply too high a discount rate, reflecting the myopic lack of concern about one's retirement resources that is a key reason for our having Social Security to begin with. By contrast, distributional outcomes depend on actual, not perceived, tax rates.

6) Other misperceptions - The question of how perceived marginal rates compare to actual rates is not limited to Social Security. For many benefits, most people probably lack any detailed understanding of how the income phase-outs work. This lack of understanding could cause perceived marginal rates to be either higher or lower than actual ones. For example, perceived rates might be higher when people mistakenly believe that they will lose Medicaid benefits immediately upon phasing out of TANF, rather than after a twelve-month delay.22 Or, going the other way, they "may not recognize the work incentives built into the EITC, since nearly all receive their payments as a lump sum based on their work during the prior year."23

7) The choice of income range for measuring marginal rates-Marginal rate tables typically show the extra net tax associated with each extra dollar of earnings. What really matters, however, for both incentive and distributional purposes, is the set of choices that people actually face. Thus, suppose that one's only work options were to spend the entire year either in a part-time job, which paid the federal minimum wage (currently $\$ 5.15$ per hour) for twenty-five hours per week, or in a full-time job that paid the same hourly rate for forty hours. One's only choices, therefore, assuming a fifty-week work year, would be to earn $\$ 0, \$ 6,437.50$, or $\$ 10,300$. Under these circumstances, only the marginal rates between the

21. Laurence J. Kotlikoff \& Jeffrey Sachs, It's High Time to Privatize, 15 Brookings Rev. 16, 17 (1997).

22. Norma B. Coe et al., Does Work Pay: A Summary of the Work Incentives UNDER TANF 5 (1998).

23. Id. at 6. 
three possible end points would matter, as opposed to those for any given extra dollar between the end points.

While this example may be too restrictive, workers often do not have the full range of dollar-by-dollar choices that typically are portrayed on economists' labor supply graphs. Job opportunities may be limited, and may involve weekly or annual time requirements that are not freely negotiable. Thus, if work choices tend to group at particular broad margins, such as those between full-time and half-time minimum wage work, attention should focus on the marginal rates that apply to these broad ranges, and the dollar-by-dollar picture may not really be what matters.

8) The choice of time period for measuring marginal rates-A final difficulty in determining relevant marginal rates concerns the choice of time period. Thus, consider the rule under which one may lose Medicaid benefits twelve months after leaving the welfare rolls. A rational and wellinformed worker would disregard this future loss of benefits if she did not expect to be off welfare for the full twelve months. Suppose, however, that she is considering a significant life change that might keep her permanently off Medicaid once the grace period has passed. Under these circumstances, the pending loss of what may be extremely valuable healthcare benefits (especially if she has several children and her employer would not offer health insurance coverage) may be important despite the grace period. The time frame people use is hard to discern, however.

Despite all these issues, several studies have tried to measure the marginal rates that low-income households face. The general pattern is low rates at the very bottom, which rapidly become extremely high, commonly exceeding seventy percent or even one hundred percent over significant ranges, and that may not decline to more normal levels until well past the official poverty line. ${ }^{24}$

Due to a lack of integrated data concerning the application of both tax and transfer programs, marginal rate studies have generally relied on applying the rules on the books to actual or simulated households. In 2005, however, Stephen Holt, making use of integrated Wisconsin data, presented a study, based on extensive data from actual poor and nearpoor households, that is the first of its kind. ${ }^{25}$

The "good" news, such as it is, from the study is that marginal rates for low-income households often fall short of the stratospheric levels suggested by simulations, due to widespread non-participation by poor households in benefit programs for which they are likely to be eligible, eliminating the effect of the phase-outs. Thus, consider single parents with two children and incomes under $\$ 18,000$, who were highly likely to be eligible for all five of the income support programs in the study

24. See Shaviro, supra note 20; Linda Giannarelli \& Eugene Steuerle, The Twice-Poverty Trap Faced by AFDC Recipients (1995).

25. Stephen D. Holt, Making Work Really Pay: Income Support and Marginal Effective Tax Rates Among Low-Income Working Households (2005). 
(TANF, Food Stamps, Medicaid, and Wisconsin's distinctive health insurance and subsidized childcare programs). Within this population, eight percent participated in none of the programs, and fewer than a third participated in more than three. ${ }^{26}$

Needless to say, non-participation by eligible households is not actually good news, if they have been made eligible for a reason. Even wholly voluntary non-participation, such as out of a sense of self-reliance, can have effects on children who were not the ones deciding to opt out. It is even less benign if resulting from administrative obstacles, lack of information, or fear of stigma associated with being a claimant. Where broader participation is not considered desirable, curtailing eligibility would be a more straightforward way of accomplishing it.

For households that participate in all of the transfer programs, the resulting overall marginal rates through the phase-out ranges can be staggering. Consider a single parent in Wisconsin with two children who participates in all five of the programs, as well as claiming the federal and Wisconsin EITCs, and whose annual income increases from $\$ 15,000$ to $\$ 35,000$. This is an example of what we might ordinarily think of as escaping poverty through hard work and self-improvement. Such an increase in income would result if the single parent moved from a full-time job (defined as two thousand hours per year) paying $\$ 7.50$ per hour to one paying $\$ 17.50$ per hour. According to the Wisconsin data, this would not increase the household's net disposable income. In other words, the marginal tax rate for such a household, for the range from $\$ 15,000$ to $\$ 35,000$ as a whole, is one hundred percent if the parent takes care to participate in all relief programs for which the household is eligible. Results are similar for other households at typical margins. ${ }^{27}$

These results pertain only to one state, and would probably be less dire, from the marginal rate standpoint, in states that offer less generous benefits than Wisconsin. In at least one respect, however, Wisconsin's marginal rates on poor and near-poor households may be unusually low. Wisconsin mitigates the marginal rate effect of losing Medicaid benefits when one's income rises above the threshold by offering more gradually phased-out, income-conditioned health insurance for children.

Insofar as the Wisconsin data is nationally representative, however, it is clear that, when poor and near-poor households participate in multiple programs that are meant to help them, they may face marginal rates that far exceed acceptable levels. The effect on behavior remains uncertain, given that a lot of the marginal rate effects are hard for people to figure out. However, empirical studies suggest that poor households do indeed respond to economic incentives created by the fiscal system. ${ }^{28}$ People

26. Id. at 5 .

27. The marginal rate is roughly one hundred percent for a single parent household with one child when its income increases from $\$ 20,000$ to $\$ 30,000$, and for a two-parent, two-child household when its income increases from $\$ 20,000$ to $\$ 35,000$. Id. at D-4, D-5.

28. See, e.g., Nada Eissa \& Hilary Hoynes, Behavioral Responses to Taxes: Lessons from the EITC and Labor Supply (Nat'l Bureau of Econ. Research, Working Paper No. 
might respond even without understanding how all the rules work if they observe, for example, that hard-working neighbors do not seem to be doing much better than those who work less.

Why do we have marginal rates in the neighborhood of one hundred percent across broad swathes of income in the lower ranges, when almost no one would openly advocate such rates? Fiscal language is unlikely to be the sole cause. The fact that so many different programs, even just on the transfer side, are designed and operated separately without full coordination may also play a role. In addition, there is a political explanation for the pattern, if those on the very bottom of the economic ladder are the most appealing cases for support and voters are reluctant to pay more in order to help those who are just a bit higher up. Lowering marginal rates for people who are beginning to escape poverty would likely require either giving smaller grants at the bottom or raising marginal rates for people above the near-poor income level. Nonetheless, given the awkwardness of openly and explicitly imposing marginal rates anywhere near one hundred percent, it seems likely that a more integrated view of taxes and transfers, both in general and for purposes of assessing marginal rates, would make the existing rate structure harder to maintain.

\section{WHAT SHOULD THE MARGINAL RATE STRUCTURE LOOK LIKE?}

So far, we have seen that (1) marginal rates need not be graduated in order for the fiscal system to be progressive, but (2) in practice they often are much too high for poor people who participate in multiple programs. The latter point, however, is intuitively the more salient. Marginal rates approaching or exceeding one hundred percent are easy to dislike. On the former point, however, even if marginal rates do not have to be graduated in order for the system to be progressive, this does not tell us whether they should be graduated.

Nearly all people favor-or think they favor-either graduated or flat marginal rates. And even (though not exclusively) among people who say they favor flat rates, it is common to agree that the marginal rate ought to be zero at the very lowest income levels (for example, at the levels needed to purchase basic necessities). So, it is worth exploring briefly why marginal rates not only need not be, but possibly should not be, graduated even if one favors significant redistribution from richer to poorer individuals.

Those who support rate graduation, and who have simply failed to appreciate the benefit phase-out component of actual marginal rates, often base the argument for it on declining marginal utility, or the point that, the more money you have, the less each dollar affects your well-being. Thus, suppose that both Bill Gates and a single mother, who has two

11729, 2004); Bruce D. Meyer \& Dan T. Rosenbaum, Making Single Mothers Work: Recent Tax and Welfare Policy and Its Effects (Nat'l Bureau of Econ. Research, Working Paper No. 7491, 2000). 
children and is working at a minimum-wage job, were to be taxed at thirty percent. The fact that losing thirty cents out of every extra dollar of income would have a greater negative impact on the single mother and her family (even if they are getting cash grants) than on Bill Gates and his family provides a reason for favoring rate graduation.

There is a countervailing factor, however, first brought to light in the Nobel Prize-winning work of economist James Mirrlees. ${ }^{29}$ Everyone, and not just poor people, is subject to the tax rate at low income brackets. The overall tax paid by Bill Gates, for example, depends on the marginal rates that apply to each dollar of his income, from the first to the last. Having a low marginal rate in lower income brackets, therefore, has a huge revenue impact. But, it has a relatively small distortionary impact on behavior, because people in higher brackets face a different set of incentives at the margin. If I am earning one million dollars, for example, none of the alternative payoffs I may consider is likely to be affected by the marginal tax rate for income levels under several hundred thousand dollars.

Inquiry into optimal rate structures, given these sorts of considerations, has prompted an entire genre in public economics research, known as the optimal income tax literature..$^{30}$ While this literature, not surprisingly, yields varying results, it often finds that "optimal marginal tax rates will be high at the bottom of the income scale (and possibly higher than at middle or upper levels of income)." 31 High at the bottom does not, however, mean approaching one hundred percent. Rather, low-income marginal rates tend to be in the forty to sixty percent range, although some specifications lead to their being below thirty percent or above eight percent. ${ }^{32}$

In sum, to say that marginal rates ought generally to be graduated is a bit like prescribing penicillin before examining the patient. Marginal rates are a technical detail, albeit an important one, in designing the fiscal system, and are best evaluated in combination with other features, such as the transfers available at the bottom, as well as the tax base to which the rates apply. Rates approaching one hundred percent are unlikely to be desirable at any margin or range where significant numbers of people are actually making work decisions. However, relative rates, which is the concern raised by interest in rate graduation, are of little independent interest, other than as a technical design detail.

29. James Mirrlees, An Exploration in the Theory of Optimum Income Taxation, 38 REv. OF ECON. STUd. 175 (1971).

30. See, e.g., Joel Slemrod, Optimal Taxation and Optimal Tax Systems, 4 J. Econ. PersP. 157, 163-66 (1990).

31. Louis Kaplow, Colloquium on Tax Policy and Public Finance, Optimal INCOME TRANSFERS 8 (2005), http://www.nyu.edu.adv/colloquia/taxpolicy/kaplow.pdf.

32. Id. 


\section{CONCLUSION}

Marginal rates are frequently analyzed based solely on taxes, without regard to benefit phase-outs that have exactly the same incentive and distributional effects as increasing positive taxes. In part, this myopia reflects the differing professional specializations of income tax and welfare experts, along with the difficulty of determining the marginal rate effects of programs with differing tax or phase-out bases and that are subject to significant interstate variation. It also, however, reflects the notion, rooted in our current fiscal language, that "taxes" and "spending" are fundamentally different.

Proposals to adopt an explicitly integrated fiscal system are often called demogrant or negative income tax proposals. These proposals appear to have no chance of enactment, partly because of their history but also because many people are uncomfortable with the notion of handing out universal and unconditional cash grants. The question of who should get income support, however, is distinct from that of how we should think about marginal rates. Cash grants can be conditional or selective, just as welfare benefits can be offered to everyone. The case for integrated thinking about the fiscal system has no necessary implications for the policies we should follow. It just permits better understanding of any given set of policies. 
